\title{
Study on the Media Arts in the Postmodern Context
}

\author{
"Symbiosis" Design of Media
}

\author{
Peng Sun \\ Dalian University of Science and Technology \\ Dalian, China
}

\begin{abstract}
Under such a postmodern context, the boundary between arts and other disciplines and among arts becomes more and more blurry. Such changes have large impacts on the lives of people. Media arts including art itself also become not that pure. "Symbiosis" exists everywhere. The artistic exploration conducted by people is the exploration process to recover the five senses of people. The development of human art history is the best evidence of five senses evolution of human. People are always experiencing the circulation of seeking for single-sense stimulation to multiple-sense stimulation. Various kinds of artistic forms always exist and the field of vision decides what people can see. The evolution of human senses will make artists continuously explore and find new artistic forms. While such artistic forms always exist but not found by human yet. The thought of "Symbiosis" enables the artists to realize the regulations of media art development. And the artists can better create through such regulations so as to serve the society.
\end{abstract}

\section{Keywords—postmodern; Symbiosis; diversification}

\section{INTRODUCTION}

What is postmodernism? The postmodernism can be considered as the concept of art history periodization which mainly refers to the series of artistic phenomena appeared in the western art circles since 1960s. The "post" in postmodernism is relative to the opinion of modernistic culture, because there are obvious divergences between postmodernism and modernism in the aspects of aesthetics orientation, mode of thinking and game rules.

The postmodernism emphasizes particularity, heterogeneity and uniqueness. The Dadaism is the most heavily impacted under postmodernism. The concept of "found object" and the view of anti-aesthetics represented by Marcel Duchamp became the most important benchmark of postmodernism artists. After that, the wide application of ready-made articles of artists has become an important symbol of Postmodernist art. The found object art not only changes the creation mode of tradition arts but the most important is that it make the range of media (materials) used by artists be enlarged infinitely.

\section{EXPLORATION ON THE "SYMBIOSIS" OF RELATED MEDIA IN THE ART}

The receptors of media and medium are the five senses of human. While the five senses include shape, sound, color, taste and touch. The media and medium have never been developed and discussed without five senses. Our daily life is the repeated process of "transfer $\rightarrow$ receive $\rightarrow$ transfer" between information and information which is also the consequence of reciprocal action of media and medium. While our sense organs play the role as carriers.

Under the post-modern context, medium has become the pronoun of sense organ outcomes and the relationship between media and medium also becomes ambiguous. Extending based on such relationship, the pronoun of medium on the aspect of architecture is space and the abstract reversibility sometimes. Similarly, from the perspective of art, if the traditional easel painting is the pure outcome of visual sense, it is not only the painting but also the art itself that become impure under the general background of postmodernism. The branches of art and schools are in mutual interdependence and integration and art and other disciplines also survive and develop by supplementing each other.

From the perspective of architecture, the Japanese master architects also attempt to explore the problems on this aspect for the thinking about this problem. Yoshinobu Ashihara thought that the internal and external space can be mutually converted and proposed the reversibility of space. And Kisho Kurokawa, the Japanese master architect further proposed the concept of "gray space". And there is also the similar theory of the philosophical view related to "medium" which is considered as a kind of philosophical view with coexisting and mutual integration and is generated during the process of compromise and mediation as well as mutual generation.

Not only that, there is also such bold trial on the aspect of clothes. The clothes brand Y-3 with the designer, Yohji Yamamoto combines sports with fashion. Although it is in bad management, we have to admit that Y-3 possesses both the touch of sports and the visual sense of beauty of fashion. And the two poles of sports and fashion which seem to be not matched are connected by certain "belt" and the originally contrary styles and features become harmonious and integrated. We must say that it is the consequence of flatting and we can also say that it is a kind of manifestation of co-existence and common prosperity. While the clothes with folds designed by Issey Miyake, the Japanese costume designer famous for folds also find the coherence point between dynamic and static states. The scheme of fold designed by Issey Miyake is permanent and he has accomplished the shape of fold during the high-tech treatment measure in organization phase which will never be out of shape. 


\section{III. "SYMBIOSIS" OF MEDIA}

"Media" definitely includes "medium" and media possess wider definitions. At the same time, the media emphasizes more on its mode, method and measure. Therefore, from the broad sense, the definitions of "media" and "medium" are connected and also possess the points respectively emphasized when going into it seriously. Under the post-modern context, we should understand the difference between media and medium from the scope of broad sense. Therefore, no matter how, "the "symbiosis design' of media" is also the "symbiosis design' of medium".

Under the post-modern context, the medium have turned to the network structure derivatization from point structure as the medium linking two or more things due to the symbiosis features of itself and media will also be no exception. Under the post-modern context, the boundaries between media and medium have become more and more ambiguous. The combination of television and network generates the network television; the combination of cellphone and network generates wap internet and internet telephony. The cellphones with functions including audible broadcast, webpage browsing, network television watching and electronic E-journal are produced at the speed of thousands of them per day. And those are all caused by the nonlinear lifestyle of people in the "symbiosis" order. And therefore, the mutual integration between media and media becomes more and more necessary.

Using technology to package the art is also a kind of "symbiosis". Through 3D technology, holographic image technology, voice recognition technology and other measures, the mode of giving language, behaviors, facial expressions and other means of expression to the static fine arts has entered our life. Under the post-modern context, to cater to the non-liner requirements and the non-liner lifestyle of people that are increasingly changed by people mentioned in the "symbiosis" order, various kinds of media are under the baptism of "symbiosis"- which means integration and decentralization. In the mean while, the meanings of the word "media" are also extending its conceptual scope with the continuous development of integration process. The "symbiosis" of media has inevitably appeared in the food, clothing shelter, transportation, vision, listening, taste, touch and mental activities of people. And I think that it is exactly a kind of "design" about the mode of integrating media together.

\section{IV. "SyMBiOSIS” DESIGN OF MEDIA}

The "symbiosis" design of media can be understood more easily in other words: the integration and deviation of media.

Currently, the earth-shaking changes are occurring to visual and acoustic modes of people. And it has become the primary task of media technical personnel since 20th century to use technology to integrate the traditional media so as to meet the non-liner demands of people. The storage mode has been switched to virtual digital storage from the physical film. While in such transfer process, the diversified integration of media becomes the final outcome. The cellphones possess multiple elements including storage, photograph, video, recording, broadcast and game. Except for visual and auditory senses, the touch has also been added in the media which is also the interactive design of media. The occurrence of resistance-type and capacitive touch screens promotes the development of man-machine interaction. Such modes existed previously, but over time, the multiple functions are integrated to meet the non-line demands and convenience of people which is an integration process. However, with the development of technology, the wish of media integration is gradually realized. And this process is also the process of "symbiosis" design.

Symbolization of body: with the extensification of the meaning of medium, the meaning of the word of medium is also extended correspondingly. The performance art which takes "body" as medium is a kind of "design" with the medium of body. The appearance and application of computers and the coming of era of mass media change the mode of receiving information of people and the bodies of human show its special position as a kind of medium. Yoko, the performance art who was active in 1960s utilized visual sense, behaviors and other modes to deliver the classifications of art in the tradition concept and the questions on the relationship between art and life. She was strongly against the traditions concept of separating art from life and advocated that the world itself is a kind of art. While she thinks that relationship between medium and media should be compound, in my opinion, the art form manifested by Yoko is the compound media art. And the idea of Yoko that the medium and media shall be in compound relationship is interlinked with the "synchronic" feature in the thought of "symbiosis".

Imaging of pronunciation: in 1995, in the installation art of Medium as Video Installation- Piano of Iwai Toshio, the Japanese artist, when the audiences use hands to touch the keyboard in front the installation like a piano, the expected music is replaced by images that are constantly changing. Iwai Toshio called it as "music plays images and images manifest music". The imaging of pronunciation and imaging of sound are like the two ends of a line. The imaging of sound is not rare around us. People can take advantage of the feature of different wave length of sound wave to manifest the sound received in the form of charts. However, without receiving the sound and without the sound source, the pure imaging of pronunciation has not been applied by people previously. And it is Iwai Toshio who finds the other "end" of this "line".

Image extension out of the two-dimension planarity: the figures and words are all images and the differences between figures and words are just like different films. Some movies can enable the audiences to receive the important information in the movies through smooth and pure images while other movies are through clear theories. Since the projection technology is improved day by day, many artists and the lovers of images carried the projectors outside and combined the images with buildings and environment since the end of 20th century which promoted the separation of images from twodimension planarity. With the development of technology, the artists and scientists use technological means to make the images closer to people. The application of holographic image eliminates the two-dimension planarity of images and the objects can be manifested in three-dimension space instead of purely on two-dimension plans. Holographic image makes use review the knowledge about visual sense. At the same time, it 
is also a kind of medium for extension of visual sense and consciousness.

Interaction of mode of transmission: interaction is an interactive phenomenon which widely exists in the lives of people. On the aspect of art, the artists combine the traditional art modes with interaction which makes the interactive art become such kind of art where people can participate in the works and communicate information on certain aspects. The interactive art enables the artists, audiences, lives and art to bond closely together. As for one network relationship, the appearance of interactive art is the good manifestation of "symbiosis" and it breaks the traditional mode between artists and audiences, integrates the works with artists and audiences and pulls the works closer to life. The relationship between artist and audiences is switched to non-line relationship from liner relationship. The interactive phenomenon gives play to its positive role on the artistic category. And there is also common interactive phenomenon in the mass media such as pay vote, election and Q \& A shows; cellphone, computer console or online game levels, opening of props; UI interface design in visual design, etc.

Diversification: since the postmodernism, the word of diversification frequently appears in various news reports and media publications. The diversification creates many "world factories". It needs to import raw materials or finished products from several countries for a vehicle from components to the complete vehicle. A cellphone manufactured in Finland needs to import the raw material of mineral from Russia and needs to be equipped with the power adapters made in China. Diversification is shuffling the production and manufacturing industry of various countries in the world. In people's daily lives, the condition with multiple roles and multiple endings in movies and teleplays has been commonly seen and the condition with multiple endings of games has also become an ordinary state. The centralized mode of thinking gradually becomes the means and measure for artists to level the art and lives.

\section{CALling OF THE TIME - "SYMBIOSIS"}

I think, since the postmodernism, different art categories mutually refer to and integrate which generates many new artistic expressions, from the perspective of art history. The art category and art are developing towards the trend of diversification. The most impressive is the exploration of artists on medium and media. I think that the artists have always been complying with a kind of order in the exploration process from the macroscopical view which, however, is not the liner order but the non-liner order. In such order, the medium is information, the relationship between medium and media is synchronic and the order that is complied with by medium is the symbiotic relationship. On the microscopic view, the artistic activities of people cannot be separated with five senses and visual activity is one of the most important senses thereinto. The visual activities of people may appear visual illusions due to multiple factors. And the visual illusions are caused by the "symbiosis" of medium.

The media arts since postmodernism are generated after the western world enters the information society, media society and highly commercialized social environment. The media art since postmodernism is a polyhedron which can reflect all aspects of contemporary society. It is full of various kinds of variables in itself. The development of media art since postmodernism is not only related to its development logic but also is related to the various kinds of cultural resources provided by the contemporary society.

The "symbiosis" is everywhere. The development of human art history is the best witness of evolution of human five senses. Human have been always seeking for the circulation from single-sense simulation to multiple-sense simulation. The inspiration of symbiosis idea on me is that the various kinds of art forms exist and what we can see depends on how large our field of vision can be. The evolution of human senses will enable us to explore and find new art forms, while such art forms always exist previously but have not been found by people. In Art and visual perception art, Arnheim thinks that the visual perception function of human has always been existing but people gradually loss the mastering on such function because we don't use it for a long time. In the book, Arnheim just guides the people on how to recover the visual function of people. Such issue can also be applicable to the development of media art which also conforms to the symbiosis idea. This means that the exploration of media art conducted by people is also the process of recovery and exploration of human five senses. Art history has become the witness of the exploration of evolution of human five senses. The "symbiosis" of media is everywhere.

\section{CONCLUSION}

Under the postmodern context, breaking the boundary of tradition is a common phenomenon where the politics, economics and culture cannot exist in closed and independent conditions. The artificial intelligence, internet, traditional industry and culture, etc are all breaking through the original boundaries and are mutually connected. Under the postmodern context, the "symbiosis" phenomenon of media will exist everywhere. If the body symbolization, imaging of pronunciation, extension of images, interaction and diversification of transmission mode are the beginning of "symbiosis", the "symbiosis" of artificial intelligence, internet and traditional industry must generate new industries and new disciplines. In the future intelligent world, maybe we will no longer need to lower our heads to play with phones and games but play in the holographic image. Maybe we only need to blink to make a phone call, use hand to place in front of chest to scratch the holographic image for ordering dishes. People will no longer need to take buses for travelling but take the pilotless automobiles and planes controlled by artificial intelligence to accomplish the travelling. All the traditional industries are all broken and all of those are brought by the "symbiosis" of media.

\section{REFERENCES}

[1] Ma Yongjian. 20 Lectures on Postmodernism. Shanghai: Shanghai Academy of Social Sciences Press, first edition in January 2006. 6. (in Chinese) 
[2] Yi Ying. Selected Works of World Art: Decline of New York. Hebei: Hebei Fine Arts Publishing House, first edition in June 2004. 3-10 . (in Chinese)

[3] Chen Ling. History of New Media Art. Beijing: Tsinghua University Press. First edition in February 2007. 48-57. (in Chinese)

[4] [Japan] Kisho Kurokawa. New Symbiosis Idea (Translated by Qin Li, Yang Xiwei, Mu Chunnuan, et al). Beijing: China Architecture \& Building Press, first edition in July 2009. 7-8.

[5] Liu Jie. New Media- Combination of Technology and Business: (academic dissertation). Shanghai: Tongji University, 2007. (in Chinese)

[6] [Japan] Ashihara Yoshinobu. External Space Design (translated by Yin Peitong). Beijing: China Building Industry Press, 1985.

[7] Sun Quanwen, Zhou Zongxian. Medium Space of Building. Beijing: China Building Industry Press, 1987. (in Chinese)

[8] [Japan] Shiraishi Kazuya. Planar Design and Trick Art (translated by Wang Chuanjie). Hebei: China Machine Press, 2008. 42-62.

[9] [America] Rudolph. Arnheim. Art and Visual Perception (translated by Teng Shouyao, Zhu Jiangyuan]. Sichuan: Sichuan People's Publishing House 1998. 2-4. 